tion is possible, or by reconstructive surgery if the skill is available.

Douglas Roy

Professor of Surgery,

Queen's University,

Belfast BT12 6BJ

I Cooper MJ, Williamson RCN. Splenectomy: indications, hazards and alternatives. $\mathrm{Br}$ f Surg

Fitzpatrick JEP, Kennedy C, McGeown MG, Oreopoulus DG, Robertson JH, Soyannwo MAO Human case of piroplamosis (babesiosis). Nature 1968;217:861-2.

Garnham PCC. Human babesiosis: European aspects. Trans $R$ Soc Trop Med Hyg 1980;74:153-5. Lanet $1977 ;$;i: $127-9$.

Okiye FD, Zeincke $\mathrm{H}$, Engen $\mathrm{DE}$, et al. Splenectomy in high risk primary renal transplant recipients. Am I Surg 1983;146:594-601.

6 Joseph TP, Wyllie GG, Savage JP. The non-operative management of splenic trauma. Aust NZ J Surg 1977;47:179-82.

\section{Management of spontaneous pneumothorax}

To drain or not to drain is the question often posed by the patient who presents with a spontaneous pneumothorax. If the pneumothorax is small (less than 20\%) and asymptomatic it may be treated conservatively on an outpatient basis-provided that the patient returns to hospital immediately if he develops breathlessness. Similarly, most people agree that active intervention with the insertion of an intercostal tube and drainage through an underwater seal is essential for patients with a tension pneumothorax and for pneumothoraces complicated by breathlessness or by an appreciable haemothorax or pyothorax.

Patients with a pneumothorax who fit neither of these categories form an important subgroup, and their management remains controversial. The conservative would argue that most large asymptomatic pneumothoraces will reexpand spontaneously over three to four weeks,' thereby avoiding the need for drainage through an intercostal tube, which is uncomfortable, needs to be left in position for an average of four days, ${ }^{2}$ and carries hazards. ${ }^{2}$ The activist (probably in the majority nowadays) would argue that tube drainage avoids prolonged inpatient and outpatient medical supervision and reduces time off work. Simple aspiration fell into disfavour because of anxieties about laceration of the lung by metal needles, but it has recently been revived successfully with the use of a Teflon intravenous cannula. ${ }^{34}$

My personal experience confirms the view that this is a simple and atraumatic way of dealing with this group of patients. The air is gently aspirated from the pneumothorax through the Teflon cannula with a $60 \mathrm{ml}$ syringe and a plastic three way tap and is expelled under water. Aspiration is stopped when resistance is felt. If four litres is aspirated with no resistance an $x$ ray film will usually confirm that no expansion has taken place, indicating that the pneumothorax is open and needs drainage through an intercostal tube. Complete aspiration without recurrence was achieved in 16 of the 23 cases reported in the two series.

Thus a group of patients with a large pneumothorax, in whom tube drainage is unnecessary, may be treated readily by simple aspiration, and this method further identifies a group in whom the pneumothorax is open and who are likely to benefit from more aggressive treatment with tube drainage and suction. The use of suction is another controversial aspect of management, ${ }^{25}$ although some of the controversy may stem from its use in cases where it is not required-for example, for a closed pneumothorax, where simple aspiration or tube drainage without suction is sufficient to re-expand the lung. Proponents of the technique believe that for patients with an open pneumothorax, suction seals the leak more rapidly by opposing the pleural surfaces. Once it is started suction should continue uninterrupted until expansion is complete and has been maintained for 24 hours. In my view, failed treatment is often due to inappropriate interruption of suction-for example, by clamping off the intercostal drain during nursing procedures or visits to the $x$ ray department.

Finally, definitive surgical treatment is required when tube drainage and suction have been unsuccessful and when, in effect, a bronchopleural fistula has formed. Furthermore, given a recurrence rate of $10 \%$ to $25 \%$, surgical prophylaxis is usually indicated after a second ipsilateral or a first contralateral recurrence, and after the initial event if the patient's lifestyle is such that a recurrence might be life threatening or highly inconvenient. In younger patients with a simple pneumothorax pleurectomy is the prophylactic procedure of choice, with a very low recurrence rate. ${ }^{67}$ In older patients with severe chronic airflow obstruction, chemical pleurodesis with talc, dextrose, or another irritant is safer but less effective.

J F RIORDAN

Consultant Physician in Thoracic Medicine,

Central Middlesex Hospital,

London NW10 7NS

Stradling P, Poole G. Conservative management of spontaneous pneumothorax. Thorax 1966; 21:145-9.

pontaneous pneumothorax: suction or no suction, early or late removal? Thorax 1982;37:46-8.

${ }^{3}$ Raja OG, Lalor AJ. Simple aspiration of spontaneous pneumothorax. $\mathrm{Br} \mathcal{J}$ Dis Chest 1981; 75:207-8

${ }^{4}$ Hamilton AAD, Archer GJ. Treatment of pneumothorax by simple aspiration. Thorax 1983;

Klassen KP, Meckstroth CV. Treatment of spontaneous pneumothorax. Prompt expansion with

aensler EA. Partial pleurectomy for recurrent spontaneous pneumothorax. Surg Gynecol Obstet

Raj Behl P, Holden MP. Pleurectomy for recurrent pneumothorax. Chest 1983;84:785.

\section{How might we improve surgical services for rural populations in developing countries?}

Any doctor who has worked in a developing country will not easily forget the widespread and pathetic evidence of surgical neglect in the villages. Huge hernias and hydroceles, unsightly lumps on the faces of women and children, and compound fractures infested with maggots bear testimony to the failure of so many countries to provide even a basic level of surgical care to their people.

Is it possible in countries where the expenditure on health is just over £1 per person a year to provide the rural population with a more comprehensive surgical service?' Probably the answer is yes-but only with a more rational use of existing resources, discarding unimaginative, inefficient, and inappropriate systems of health care delivery. We must first stop building ever more costly but politically rewarding large showpiece "disease palaces" in the big cities" to which only $20 \%$ of the population has access, ${ }^{3}$ and divert much of our material and medically trained manpower to the villages. Two important papers suggest how this might be done. 